\title{
NGAL - URINARY BIOMARKER WITH PATHOLOGIC SIGNIFICANCE IN NEPHROLOGY PRACTICE
}

\author{
Mădălina-Gabriela Stăncescuํ․ Mircea Penescu² \\ ${ }^{1}$ Department of Nephrology, "Carol Davila", Clinical Hospital of Nephrology, Bucharest \\ Department of Nephrology, "Carol Davila", Clinical Hospital of Nephrology, Bucharest
}

\begin{abstract}
Renal pathology is a pluralism of acute or chronic conditions in which the main victim is the nephron. Regardless of the nature of the injury, the primary lesion will always lead - in absence of efficient treatment - to end-stage kidney disease and renal replacement therapy. Although we are in the 21st century and amazing advances have been recorded in the medical field, the diagnosis of chronic kidney disease is performed - most frequently - based on the estimation of the glomerular filtration rate, based on serum creatinine. Unfortunately the serum creatinine level increases only when $>50 \%$ of the nephrons are already irremediably destroyed. In the last 20 years, an intensive research is performed in order to discover new plasma or urinary biomarkers for an earlier diagnosis of the renal pathology. Neutrophil gelatinase-associated lipocalin (NGAL) has a central place in this research, and its diagnostic and prognostic utility is proven particularly in acute kidney injury, but also in glomerulonephrites, diabetic nephropathy, and chronic kidney disease.
\end{abstract}

Keywords: acute kidney injury, glomerulonephrites, diabetic nephropathy, chronic kidney disease, urinary biomarker, neutrophil gelatinase-associated lipocalin.

\begin{abstract}
Patologia renală reprezintă un cumul de afecțiuni, acute sau cronice, în care victima principala este nefronul. Indiferent de natura injuriei, leziunea primara va duce, în absența tratatamentului efficient, la boală cronică de rinichi în stadiu final și terapie de substituție renală. Deși ne aflăm în secolul 21 și s-au înregistrat progrese uimitoare în domeniul medical, diagnosticul bolii cronice de rinichi se face, cel mai adesea, pe baza estimării ratei de filtrare glomerulare pe baza creatininei serice. Din păcate, nivelul seric de creatinină crește când deja $>50 \%$ dintre nefroni au fost distruși iremediabil. În ultimii 20 de ani se fac cercetări intense pentru descoperirea unor noi biomarkeri, plasmatici sau urinari, pentru diagnosticul mai precoce al patologiei renale. Lipocalina asociată gelatinazei neutrofilice (NGAL) deține un loc central în cadrul acestor cercetări, dovedindu-se utilitatea diagnostică și prognostică mai ales în injuria renală acută, dar și în glomerulonefrite, nefropatia diabetică și în boala cronică de rinichi.
\end{abstract}

Cuvinte cheie: injurie renală acută, glomerulonefrite, nefropatie diabetic, boală cronică de rinichi, biomarker urinar, lipocalina asociată gelatinazei neutrofilice. 


\section{INTERNAI}

\section{Original papers}

\section{Introduction}

Chronic kidney disease (CKD) is a general name for all the types of irreversible kidney impairment, regardless if the primary lesion is of glomerular, tubulointerstitial or vascular nature. In the present moment a true CKD epidemic is recorded, and therefore it is considered a public health issue. In 2010 it was estimated that 2618 million people worldwide benefit of renal replacement therapy ${ }^{(1)}$. A study published in 2016 estimates the prevalence of stage 3-5 CKD at $11.86 \%$ for Europe and $14.44 \%$ for USA and Canada $^{(2)}$. The prevalence is similar to the estimated prevalence for DM. CKD is associated with increased mortality and morbidity rates, decrease of work capacity, and increased healthcare system costs. In the present moment the valid definition for CKD is based on the presence of renal impairment or the decrease of renal function present for at least 3 months. The estimation of the renal function is performed most frequently by the estimation of the glomerular filtration rate, based on serum creatinine. There is a large patient category with a discreet impairment of the renal function or with acute kidney injury by various mechanisms (sepsis, post-surgery, iatrogenic, autoimmune) in whom the estimation of the renal function based on serum creatinine is subjected to errors. Early recognition of the renal impairment, previous to the increase of serum creatinine, may determine the early application of the correct treatment, with higher chances of the remission of the renal impairment. The rapid and correct application of treatment measures in acute conditions, such as primary preventive measures for patients with CKD risk, and secondary preventive measures for those with established stage 13 CKD may decrease the evolution towards end-stage kidney disease and dialysis. For these patient categories, starting with the end of the 20th century, researchers focused their attention on urinary biomarkers various substances present in the urine in different circumstances. Among the great variety of substances, remarkable is the neutrophil gelatinase-associated lipocalin (NGAL), a marker of tubular impairment, whose importance was initially demonstrated in acute kidney injury, and subsequently the studies were also extended on other types of renal pathology.

\section{NGAL - pathophysiology}

In human urine a large number of proteins and peptides can be identified. Their origin is extremely diverse: the glomerular filtration process, necrosis and cell apoptosis, surface protein proteolysis, and secretion of exosomes by epithelial cells. The first studied 


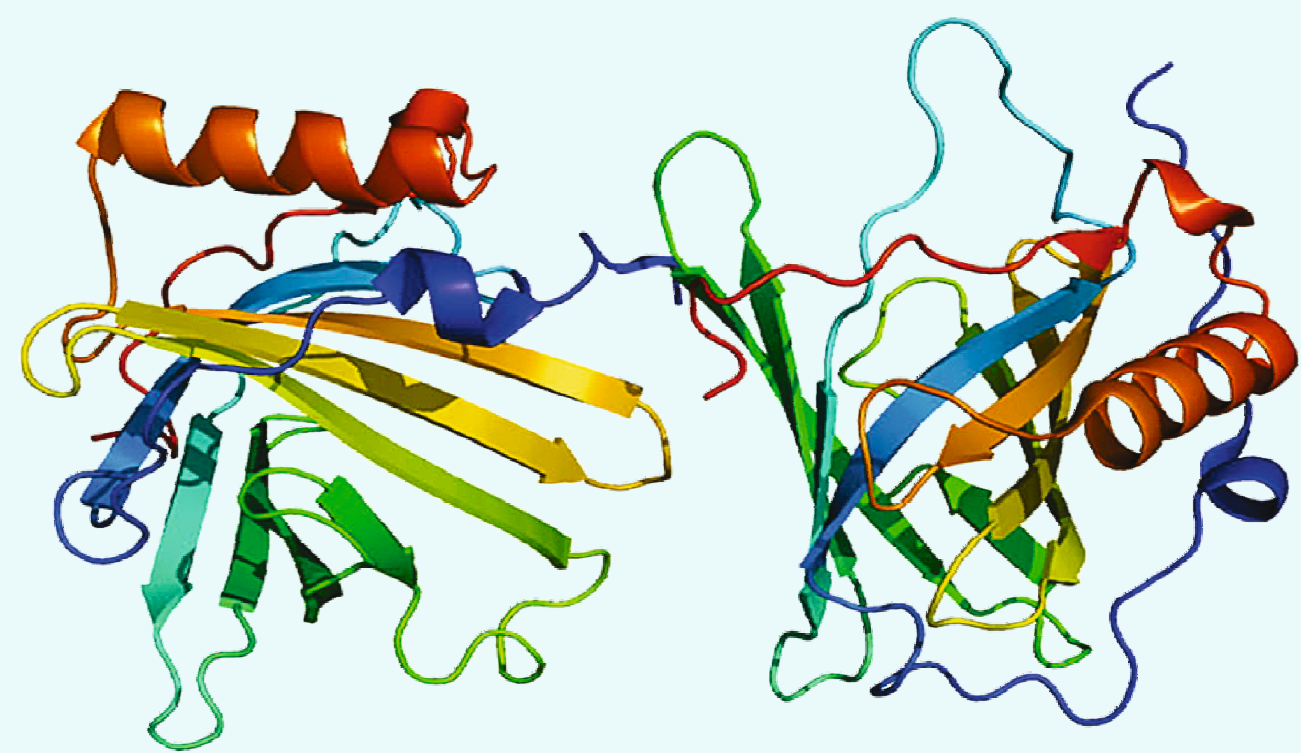

Figure 1. NGAL structure

Table 1. Ideal biomarkers in AKI should meet the following conditions

1. Non-invasive

2. Easy determination in urine or blood

3. Quick to measure

4. Low cost

5. To identify the primary localisation of the injury (proximal tube, distal tube, interstitium or vessel)

6. To distinguish between acute or chronic impairment (AKI, CKD or acute episode of CKD)

7. To identify the cause (sepsis, toxic, ischemic)

8. To differentiate the AKI subtypes (prerenal, intrinsic renal, or obstructive post-renal)

9. To differentiate AKI of other renal pathologies (glomerulonephritis, interstitial nephritis, or infections)

10. Role in risk stratification

11. Role in prognostic estimation (estimation of dialysis requirement, duration of hospitalization, mortality)

12. Monitoring of the response to treatment ${ }^{(10,11)}$ 
that focused on these urinary substances date back to the end of the 20th century. The occurrence of mass spectrometry made possible the urinary analysis of over 1000 proteins and a much more higher number of peptides, demonstrating the variability of urinary excretion rates, which can have a practical involvement in: early diagnosis of renal conditions, prognostic estimation, response to treatment ${ }^{(3)}$.

From this impressive number of proteins and peptides, many studies focused on NGAL, a protein with a molecular weight of $25 \mathrm{kDa}$, from the lipocalin family. It is also known as lipocalin 2 or siderocalin. NGAL is coded by gene LCN2, located on chromosome 9q34.11. It was first identified in 1993 in a mouse kidney cell culture infected with simian virus 40 , and subsequently in human neutrophils ${ }^{(4)}$. It is a small protein which binds and facilitates the transport of hydrophobic ligands, and sometimes intervenes in the protein-protein interaction, forming complexes with metalloproteinase 9. Depending on the status of the binding with MMP-9, NGAL is named "apo" or "holo" $N G A L^{(5)}$.

NGAL is normally expressed in several human tissues: kidney, breast, liver, lung, trachea, small bowel, bone marrow, thymus, fatty tissue, and macrophages. NGAL is completely absent from brain, heart, skeletal muscle, spleen, testicle, colon, and ovaries.
Negligible quantities of NGAL are found in pancreas, endometrium, and peripheral leukocytes ${ }^{(5)}$.

NGAL has several roles in the body. It is involved in innate immunity via iron sequestration, thus limiting bacterial development ${ }^{(5)}$. NGAL also has an important role in oncogenesis, as it is a protein with a protumoral effect which determines tumor growth and chemoresistance. NGAL expression is increased in breast cancer, oesophageal cancer, thyroid cancer, gastric cancer, and urinary bladder cancer, and also in chronic myeloid leukemia ${ }^{(5)}$.

In renal pathology the NGAL gene is one of the main genes stimulated in the kidney after an acute injury, ischemic or toxic, in animal models, leading to an increase of NGAL synthesis. Several studies demonstrated the increase of urinary NGAL as an early diagnostic biomarker in several AKI situations (after cardiac bypass interventions, after contrast medium administration, in intensive therapy units), in glomerulonephrites, and even in CKD.

\section{Acute kidney injury}

Acute kidney injury (AKI) is defined as the increase of creatinine by more than 0.3 $\mathrm{mg} / \mathrm{dL}$ within 48 hours or the increase of creatinine $\geq 1.5 \times$ the baseline value in the last 7 days or diuresis $<0.5 \mathrm{~mL} / \mathrm{kg} /$ hour in the 
Cardiac surgery associated (CSA) acute kidney tubular damage

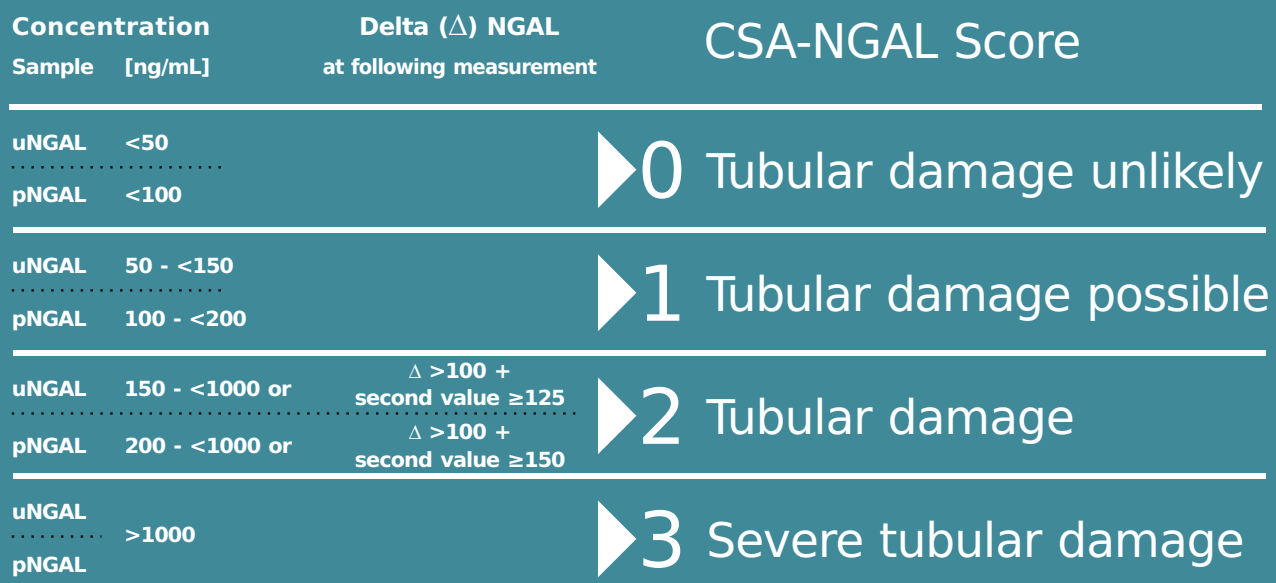

Figure 2. The CSA-NGAL score. CSA, Cardiac surgery associated; ÄNGAL, NGAL increase; CSA-NGAL score, cardiac surgeryassociated NGAL score; uNGAL, urine NGAL; pNGAL, plasma NGAL. Hilde R.H. de Geus et all, The cardiac surgeryassociated neutrophil gelatinase-associated lipocalin (CSA-NGAL) score: A potential tool to monitor acute tubular damage

\begin{tabular}{|c|c|c|}
\hline Pathology & Study & Result \\
\hline Rapidly progressive GN & $\begin{array}{l}\text { Wang F, } 2009 \text { - } 20 \text { patients with } \\
\text { ANCA-negative pauci-immune } \\
\text { vasculitis and } 22 \text { with ANCA- } \\
\text { positive pauci-immune vasculitis }\end{array}$ & $\begin{array}{l}\text { Increased serum levels of NGAL } \\
\text { in both patient categories }\end{array}$ \\
\hline \multirow{2}{*}{ IgA nephropathy } & $\begin{array}{l}\text { Ding H, } 2007-70 \text { patients with } \\
\text { IgA nephropathy, } 40 \text { control } \\
\text { patients }\end{array}$ & $\begin{array}{l}\text { Urinary NGAL and the urinary } \\
\text { NGAL/creatinine ratio are } \\
\text { associated with progressive } \\
\text { proliferation of mesangial } \\
\text { lesions and tubulointerstitial } \\
\text { lesions. }\end{array}$ \\
\hline & $\begin{array}{l}\text { Harin Rhee, } 2015 \text { - } 121 \text { patients } \\
\text { with IgA nephropathy }\end{array}$ & $\begin{array}{l}\text { Urinary NGAL with increased } \\
\text { values in patients with acute } \\
\text { tubulointerstitial lesions, } \\
\text { compared to those with chronic } \\
\text { lesions }\end{array}$ \\
\hline \multirow[t]{2}{*}{ Lupus nephritis } & \multirow{2}{*}{$\begin{array}{l}\text { María Teresa Torres -Salido, } \\
2014 \text { - } 38 \text { patients with active } \\
\text { lupus nephritis, } 56 \text { patients with } \\
\text { lupus nephritis treated with } \\
\text { partial remission, } 29 \text { patients } \\
\text { with lupus nephritis treated with } \\
\text { total remission, } 23 \text { patients with } \\
\text { SLE without renal lesions, and } \\
35 \text { healthy volunteers }\end{array}$} & $\begin{array}{l}\text { FE NGAL/FE protein - activity } \\
\text { marker in patients with active } \\
\text { lupus nephritis compared to } \\
\text { patients with inactive lupus } \\
\text { nephritis or control patients. }\end{array}$ \\
\hline & & $\begin{array}{l}\text { Persistently increased serum } \\
\text { NGAL - prognostic marker for } \\
\text { progression towards end-stage } \\
\text { CKD }\end{array}$ \\
\hline
\end{tabular}

Table 2. Current studies that were aimed at assessing NGAL in patients with glomerulonephrites 


\section{INTERNAI}

\section{Original papers}

last 6 hours. (6) A meta-analysis published in 2013 estimated than 1 in 5 adults (21.6\%) and 1 in 3 children (33.7\%) were diagnosed with AKI (using the definition of KDIGO published in 2004) between 2004 - 2013. Increased incidence rates were determined in hospitalized patients, especially in those in intensive therapy departments or after cardiovascular surgery, in contrast with community-acquired AKI cases. The recorded mortality was $23.9 \%$ in adults and $13.7 \%$ in children ${ }^{(7)}$. AKI can be a precursor of end-stage kidney disease, $\sim 13 \%$ of patients with $\mathrm{AKI}$ requiring dialysis in the next 3 years $^{(8)}$.

In cardiology, the discovery of troponin as diagnostic biomarker in acute coronary syndromes allowed the identification of ischemic changes within the first hours, and the application of various efficient treatment methods, leading to the significant decrease of mortality by $\sim 50 \%$. Unfortunately the diagnosis and treatment of AKI did not change during the last 60 years. The diagnosis of AKI is still based on the increase of serum creatinine, and the treatment, often implemented tardily after the occurrence of the first renal changes, consists especially of measures to sustain vital functions, explaining the high morbidity and mortality rates associated with AKI.

Serum creatinine, based on which the glomerular filtration rate is calculated, is far from being an ideal biomarker, as the serum level is influenced by many factors (age, gender, muscle mass, diet, medication, amputations, hydration status). In AKI, the increase of serum creatinine is recorded tardy after the occurrence of anatomopathological lesions, when $>50 \%$ of nephrons were already destroyed (after 48-72 hours) and does not distinguish between the different types of renal impairment (prerenal azotemia, intrinsic renal impairment, or obstructive uropathy). Therefore it was considered a necessity to identify other biomarkers which are capable to diagnose the AKI early. Early identification of AKI, previous to the development of azotemia, can increase the recorded morbidity and mortality.

In 2005 the American Nephrology Society designated the discovery of urinary biomarkers for the early diagnosis of AKI as a top priority research area(8).

NGAL is one of the main urinary biomarkers studied in AKI patients. NGAL is the only urinary biomarker which was studied in both blood and urine. A meta-analysis published in 2016 shows that urinary NGAL correlates better with AKI than plasmatic NGAL. Plasmatic NGAL predicts better the acute inflammation than the degree of renal impairment in AKI. Plasmatic NGAL is produced in other organs (lungs, liver), neutrophils and circulatory macrophages in 
specific stimulation conditions, thus the predictive capacity pf plasmatic NGAL for AKI is low compared to urinary NGAL. Plasmatic NGAL may represent a solution in patients with AKI with oliguria or anuria, in whom the collection of an urine sample is impossible ${ }^{(9)}$. Urinary NGAL is less affected by extrarenal synthesis. Systemically produced NGAL is filtered in the glomerules and subsequently is reabsorbed in the proximal convoluted tubule. Decrease of glomerular filtration associated with AKI leads to the decrease of NGAL in the the primary urine. In addition, studies of genetic expression of NGAL in AKI shows an "upregulation" phenomenon of messenger RNA for NGAL in the Henle loop and the distal nephron, immediately after the traumatic event, leading to the increase of NGAL secretion in the final urine ${ }^{(9,17)}$.

In early phases of AKI, urinary NGAL has a protective effects by binding excess iron, thus limiting its toxicity. In late phases, NGAL stimulates cell proliferation also by regulating the iron metabolism ${ }^{(17)}$.

In a study published in 2003, Mishra et al. identified increased urinary levels of NGAL in animal models with renal ischemia ${ }^{(12)}$. These results encouraged studies on human participants, and until now there is a considerable number of studies which confirm the diagnostic value of NGAL in AKI patients after cardiovascular surgery, administration of contrast medium or hospitalized in intensive therapy units. All studies demonstrate that urinary excretion of NGAL increases early after renal injury $(<2$ hours) compared to the control group ${ }^{(13-16)}$.

Based on the promising results of the studies, in 2016 a few experts in intensive therapy and nephrological intensive therapy created the CSA-NGAL score (cardiac surgery associated acute kidney tubular damage). This group of experts define acute kidney tubular damage as a stage precursory of AKI, subclinical, diagnosed by the increase of serum and urinary level of NGAL. Based on this score it is possible to identify patients with risk of developing manifest $\mathrm{AKI}$, and it is possible to apply early preventive measures and/or treatment ${ }^{(17)}$. Observational and interventional prospective studies are needed to validate the CSA-NGAL score for the diagnosis and prognosis of patients with subclinical AKI.

In a study published in 2007, Dent $C$ et al. showed that the plasmatic NGAL level is correlated with patient prognosis after cardio-pulmonary by-pass surgery. The plasmatic NGAL concentrations determined at 2 hours was the strongest predictor of AKI (sensitivity 0.96 , specificity 0.94 ), correlated with the level of creatinine, duration of AKI, and duration of hospitalization. The level of plasmatic NGAL at 12 hours was strongly correlated with mortality ${ }^{(18)}$.

As for the estimation of dialysis requirement in AKI patients, the results of studies are divided. A meta-analysis published in 2018 shows that the results of studies which investigated the prognostic capacity of NGAL for the requirement of renal replacement therapy in AKI patients are heterogeneous, with the AUC for NGAL varying between 0.47 and 0.88. Urinary NGAL is encountered in several forms (mono-, homo-, or heterodynamic) depending on its origin (systemic or urinary), and tests which exist in this time point for determination of NGAL use different antibody combinations, which may explain the various results of the prognostic capacity of NGAL ${ }^{(19)}$.

Due to the fact that AKI is an extremely complex pathology in which the pathophysiological event are in rapid succession, it is unlikely that a single biomarker could meet the conditions of an 


\section{INTERNAL}

\section{Original papers}

urinary biomarker. Researchers seem to have come to an agreement that a combination of biomarkers is needed for early diagnosis and estimation of prognosis in AKI. Studies performed until now indicate that NGAL will play a central role, as the results seem to conform its importance in AKI. Subsequent studied are needed to establish the optimal combination of biomarkers for the early diagnosis of AKI.

\section{Glomerulonephrites}

Glomerulonephrites (GN) represent a heterogeneous group of pathologies which primarily affect the renal glomerule, as the tubular, interstitial or vascular damage is secondary. Based on their evolution, glomerulonephrites are classified in acute, rapidly progressive and chronic. The prototype of acute glomerulonephrites is the acute poststreptococcal glomerulonephritis, which in most cases has an autolimited evolution. The other two categories of glomerulonephrites have a different evolution pattern towards end-stage CKD:

- Rapidly progressive glomerulonephritis (RPGN) - 90\% - end-stage CKD in a few weeks or months

- Focal segmental glomerulosclerosis (FSGS) - 80\% - end-stage CKD in 10 years

- Membranous nephropathy - 20-30\% end-stage CKD in 10 years
- Membranoproliferative glomerulonephritis: $40 \%$ - end-stage CKD in 10 years

- Lupus nephritis - $20 \%$ - end-stage CKD in 10 years

- IgA nephropathy - 10\% - end-stage CKD in 10 years $^{(20)}$

Chronic GN is the third cause of end-stage CKD, as $10 \%$ of dialysed patients have this diagnosis. In Romania, one of six dialysed patient suffers from chronic $\mathrm{GN}^{(21)}$.

The diagnostic golden standard for $\mathrm{GN}$ is renal punch biopsy. As it is an invasive manoeuvre, it performing is not without complications: macroscopic hematuria, perirenal hematoma, hypovolemic shock, infections, kidney deterioration. Renal punch biopsy is contraindicated in patients with renal tumors, single kidney, anemia, coagulation disorders, and in case of patient refusal. In all these patient categories, the diagnosis of GN cannot be made. In addition, renal punch biopsy offers information on associated tubulointerstitial damage and the ratio of acute / chronic lesions. Current studies suggest that tubulointerstitial damage causes the evolution of GN towards end-stage kidney disease. Differentiation between the acute and chronic lesion types is extremely important, as the treatment is completely different. The active glomerular or tubular lesions require aggressive 
immunosuppressive treatment, while a high score of chronic lesions suggests an evolution towards end-stage kidney disease and the requirement of measures to slow the progression (control of BP, proteinuria, low protein diet). Choosing the optimal treatment is extremely important, considering the toxicity of immunosuppressive treatment and the associated adverse reactions.

Considering all these, urinary biomarkers should offer useful diagnostic and prognostic information until obtaining the result of the renal punch biopsy or in situations where it is contraindicated. The quick and easy obtaining of these useful information may contribute to rapid initiation of treatment and significant improvement of the prognosis, especially in patients with rapidly progressive GN. Urinary biomarkers can be found useful also in patients with renal punch biopsy in the assessment of the response to treatment, or for the diagnosis of relapses.

NGAL is a biomarker of tubulointerstitial damage with demonstrated diagnostic efficacy in AKI patients. Considering the fact that tubulointerstitial damage is common in $\mathrm{GN}$, and that tubular lesions drive the prognosis, the assessment of NGAL in patients with glomerulonephrites seemed an interesting perspective.

\section{Diabetic nephropathy}

Diabetic nephropathy (DN) is a clinical syndrome defined by: persistent albuminuria $>300 \mathrm{mg} /$ day at least 2 determinations at a 3-6 months interval, progressive nitrogen retention, and hypertension. Diabetic nephropathy is one of the microvascular complications of DM, and it is the most common cause of end-stage CKD, as 30$40 \%$ of dialysed patients have DM.
The main changes which occur in the kidney are the glomerular changes: impairment of capillary endothelium, of mesangial cells and of podocytes, with the increase of extracellular matrix synthesis which will cause the thickening of glomerular basal membrane, Kimmelstiel-Wilson nodes, and mesangial expansion. The glomerular impairment is manifested clinically by proteinuria. Recent studies show that tubulointerstitial damage also has an important role in the pathogenesis of DN. The hemodynamic and metabolic disturbances (glomerular hyperfiltration, hyperglycemic status) also have consequences on the epithelial cells of the proximal convoluted tubules. The prolonged exposure of the cells of the proximal convoluted tubules to these stressing factors causes synthesis of profibrotic cytokines, with accumulation of extracellular matrix and the occurrence of tubular fibrosis. In addition, glomerular impairment worsens the tubulointerstitial lesions. The decrease in number of nephrons leads to the decrease of filtration pressure in intact nephrons, leading to worsening of the tubulointerstitial fibrosis ${ }^{(26)}$. The tubular impairment precedes the occurrence of microalbuminuria, thus its detection via noninvasive methods prior to the occurrence of microalbuminuria can detect patients with risk of development of diabetic nephropathy. In a study published in 2012, performed in 30 patients with type 2 DM with hyperfiltration, 58 patients with type 2 DM with normal GFR, and 24 control patients, authors have demonstrated increased urinary values of NGAL and decreased serum levels in the group of patients with hyperfiltration compared to the group of patients with normal GFR. The serum and urinary NGAL values recorded the same trend in patients with normal GFR compared to the control 


\section{INTERNAL}

\section{Original papers}

group. However no statistically significant difference was recorded for the urinary NGAL values between the 3 patient groups. The authors have concluded that the increased values of the urinary excretion of NGAL in diabetic patients with hyperfiltration compared to those with normal GFR and the control group supports the theory of tubular impairment in the setting of hyperfiltration ${ }^{(27)}$. The results of the studies performed in patients with established DN do not support the importance of NGAL for the prognosis of evolution towards end-stage CKD. Nielsen et al. demonstrated in a study published in 2011 that the urinary NGAL level does not represent an independent prognostic marker for the CKD progression and does not bring any information additional to consecrated prognostic markers (proteinuria, BP) ${ }^{(28)}$. Therefore, monitoring of serum and urinary NGAL levels seems useful in patients with DM without DN, and it may represent an early screening method of patients with DN risk, as the studies show changed levels already in the stage of hyperfiltration ${ }^{(27)}$ The intensification of hypoglycemic treatment, the strict control of BP and associated risk factors already in this stage in patients with increased risk may lead to an improvement of prognosis.

Although rarely cited in literature, there are cases of patients with DM with renal function impairment and significant proteinuria, but without DN. For differential diagnosis in these patients renal punch biopsy is required. The study of urinary biomarkers, including NGAL, could offer prognostic and diagnostic information complementary to the renal punch biopsy.

\section{Chronic kidney disease}

CKD is in the present time a public health issue, as more then $10 \%$ of the population worldwide is suffering of this pathology. It is associated with an increased morbidity and mortality, of both general and cardiovascular cause. Significant efforts were made to identify patient groups who are recording a rapidly progressive impairment of the renal function, compared to those with renal function stationary for a longer time period. In the present time, the main predictors of negative prognosis in CKD patients are uncontrolled hypertension and the degree of albuminuria. However studies have shown that often the estimation of the risk of progression towards ESRD is deficient, bringing into discussion new possibilities of standardization and a more accurate estimation of the risk.

In CKD, regardless of its etiology, tubulointerstitial lesions are a final evolution pathway, and their severity dictate the response to treatment and the patient prognosis. In a study published in 2013, it is 
sustained the urinary NGAL / creatinine ratio is an additional prognostic factor for the evolution towards ESDR in elderly Caucasian patients, with low proteinuria. As it is a marker of tubular lesion, NGAL estimates better the severity of tubular lesions compared to albuminuria. Albumin is filtrated in glomerules and reabsorbed in tubules; the presence of albuminuria is correlated especially with glomerular lesions, and secondarily with tubular lesions ${ }^{(30)}$.

Studies have shown the importance of NGAL in the early detection of $A K I$, and therefore a premise was arisen for the utility of NGAL in the differential diagnosis of AKI and CKD in patients who present renal dysfunction without a medical history. Seref Kerem Corbacioglu et al. in 2017 showed that the serum level of NGAL was higher in patients with AKI compared to patients with CKD, but with values with low sensitivity and specificity $^{(30)}$. Additional studies are needed to establish the role of NGAL in patients with CKD.

\section{Conclusions}

Until the present time point, studies have shown that NGAL is an extremely valuable biomarker in the early diagnosis of AKI - a pathology which still has a high morbidity and mortality. The early diagnosis of AKI based on NGAL or a combination of biomarkers focused on NGAL seems promising and may lead to a significant improvement of the prognosis. The use of NGAL for the diagnosis and prognosis od glomerulonephrites or other renal pathologies is less documented, and the results of the studies did not yet manage to bring enough evidence to support the uppermost importance of NGAL in other pathologies. This aspect is not necessarily a negative one, but it rather highlights the importance of NGAL for the diagnosis of extended tubular lesions associated with AKI, leaving space for other biomarkers, specific for the remainder of the renal pathology, with NGAL maintaining a second role.

\section{References}

1. Liyanage $T$ et all Worldwide access to treatment for end-stage kidney disease: a systematic review. Lancet 2015 May; 385 (9981):1975-82. Epub 2015 Mar 13

2. Nathan $R$ Hill et all Global Prevalence of Chronic Kidney Disease A systematic Review and Meta-Analysis. PloS One 2016; 11(7): e0158765

3. Trairak Pisitkun et all, Discovery of Urinary Biomarkers Molecular \& Cellular Proteomics October 1, 2006, First published on July 12, 2006, 5 (10) 1760-1771;

4. Kjeldsen $L$ et all Isolation and primary structure of NGAL, a novel protein associated with human neutrophil gelatinase. J Biol Chem. 1993 May 15;268(14):10425-32.

5. Monisha J et all. Neutrophil Gelatinase-Associated Lipocalin (NGAL): A Promising Biomarker for Cancer Diagnosis and A Potential Target for Cancer Therapeutics. J Cell Sci Molecul Biol. 2014;1(2): 106.

6. KDIGO Clinical Practice Guideline for Acute Kidney Injury

7. Susantitaphong $P$ et all World Incidence of AKI: A Meta-Analysis. Clin J Am Soc Nephrol. 2013 Sep 6; 8(9):1482-1493

8. American Society of Nephrology Renal Research Report JASN July 20105,16 (7) 1886-1903; DOI: https://doi.org/10.1681/ASN.2005030285

9. Zhou $F$ et all Diagnostic value of neutrophil gelatinase-associated lipocalin for early diagnosis of cardiac surgery-associated acute kidney injury: a metaanalysis European Journal of Cardio-Thoracic Surgery, Volume 49, Issue 3, 1 March 2016, Pages 746755, https://doi.org/10.1093/ejcts/ezv199

10. Sachin S. Soni et all Early Diagnosis of Acute Kidney Injury: The Promise of Novel Biomarkers Blood Purif 2009;28:165174 DOI: 10.1159/000227785 Published online: July 8, 2009

11. Taub Pam et all Role of Biomarkers in the Diagnosis and Prognosis of Acute Kidney Injury in Patients With Cardiorenal Syndrome Expert Rev Cardiovasc Ther. 2012;10(5):657-667.

12. Jaya $M$ et all Identification of neutrophil gelatinaseassociated lipocalin as a novel early urinary biomarker for ischemic renal injury. J Am Soc Nephrol 2003;14:25342543.

13. Jaya $M$ et all: Neutrophil gelatinase-associated lipocalin (NGAL) as a biomarker for acute renal injury after cardiac surgery. Lancet 2005;365:1231 1238.

14. Dent CL et all: Plasma neutrophil gelatinase- 


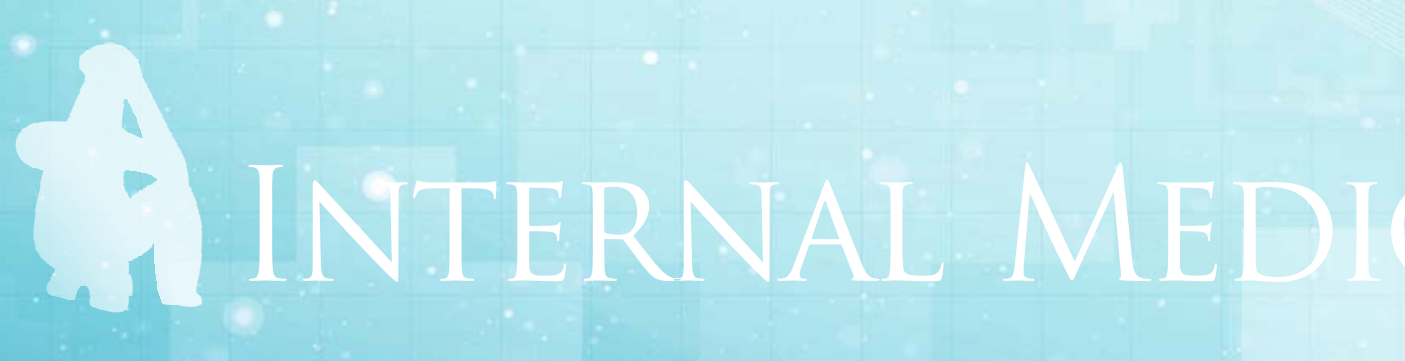

Original papers

associated lipocalin predicts acute kidney injury, morbidity and mortality after pediatric cardiac surgery: a prospective uncontrolled cohort study. Crit Care 2007;11:R127.

15. Hirsch R, et all: NGAL is an early predictive biomarker of contrast-induced nephropathy in children. Pediatr Nephrol 2007;22:20892095.

16. Zappitelli $M$ et all: Urine neutrophil gelatinase associated lipocalin is an early marker of acute kidney injury in critically ill children: a prospective cohort study. Crit Care 2007; 11:R84

17. de Geus HR et all, The cardiac surgeryassociated neutrophil gelatinase-associated lipocalin (CSA-NGAL) score: A potential tool to monitor acute tubular damage J Thorac Cardiovasc Surg. 2016 Jun;151(6):1476-81. doi: 10.1016/j.jtcvs.2016.01.037. Epub 2016 Feb 12.

18. Dent $C$ et all Plasma neutrophil gelatinase-associated lipocalin predicts acute kidney injury, morbidity and mortality after pediatric cardiac surgery: a prospective uncontrolled cohort study Crit Care. 2007; 11(6): R127.Published online 2007 Dec 10. doi: 10.1186/cc6192

19. Klein S, Biomarkers for prediction of renal replacement therapy in acute kidney injury: a systematic review and meta-analysis Intensive Care Med. 2018; 44(3): 323336.Published online 2018 Mar 14. doi: 10.1007/s00134-018-5126-8

20. Batuman V Chronic Glomerulonephritis Feb 01, 2017,www.medscape.com

21. Mircescu G Glomerulopatiile, Ed enciclopedica, Bucuresti, 2016

22. Ding $H$ Urinary neutrophil gelatinase-associated lipocalin (NGAL) is an early biomarker for renal tubulointerstitial injury in IgA nephropathy. Clin Immunol. 2007 May;123(2):227-34. Epub 2007 Mar 13.

23. Wang $F$ Neutrophil degranulation in antineutrophil cytoplasmic antibody-negative pauci-immune crescentic glomerulonephritis. J Nephrol. 2009 Jul-Aug;22(4):491-6.
24. Torres-Salido MT et all Neutrophil gelatinaseassociated lipocalin as a biomarker for lupus nephritis Nephrology Dialysis Transplantation, Volume 29,Issue 9, 1 September 2014, Pages 17401749, https://doi.org/ 10.1093/ndt/gfu062

25. Rhee $H$ et all, High serum and urine neutrophil gelatinase associated lipocalin levels are independent predictors of renal progression in patients with immunoglobulin A nephropathy Korean J Intern Med. 2015 May; 30(3): 354361.Published online 2015 Ap doi: 10.3904/kjim.2015.30.3.354

26. Tramonti $G$ Review and Discussion of Tubular Biomarkers in the Diagnosis and Management of Diabetic Nephropathy Endocrine. Author manuscript; available in PMC 2014 Jun 1.Published in final edited form as: Endocrine. 2013 Jun; 43(3): 494503. Published online 2012 Oct 20. doi: 10.1007/s12020-012-9820-y

27. Fu WJ et all. Changes of the tubular markers in type 2 diabetes mellitus with glomerular hyperfiltration. Diabetes Res Clin Pract. 2012;95:105109.,

28. Stine E. Nielsen et all, Tubular markers do not predict the decline in glomerular filtration rate in type 1 diabetic patients with overt nephropathy Kidney Int. 2011 May;79(10):1113-8. doi: 10.1038/ki.2010.554. Epub 2011 Jan 26.

29. Edward R. Smith and all Urinary neutrophil gelatinase-associated lipocalin may aid prediction of renal decline in patients with non-proteinuric Stages 3 and 4 chronic kidney disease (CKD) Nephrology Dialysis Transplantation, Volume 28, Issue 6, June 2013, Pages 15691579,https://doi.org/10.1093/ndt/gfs586 Published:16 January 2013

30. Corbacýoglu, SK et al. "Value of plasma neutrophil gelatinase-associated lipocalin (NGAL) in distinguishing between acute kidney injury (AKI) and chronic kidney disease (CKD)." Turkish journal of emergency medicine vol. 17,3 85-88. 3 Jun. 2017, doi:10.1016/.tjem. 2017. 03.002 